\title{
Gene Editing and the Environment (the International Legal Challenges)
}

\author{
Vitaly Kvashis ${ }^{1}$, Olga Tsokolova $^{1}$, and Yulia Sluchevskaya ${ }^{2 *}$ \\ ${ }^{1}$ All-Russian Research Institute of the Ministry of Interior Affairs of the Russian Federation, Moscow, Russia \\ ${ }^{2}$ Saint-Petersburg University of the Ministry of Interior Affairs of the Russian Federation, Kaliningrad Branch, Kaliningrad, Russia
}

\begin{abstract}
The article examines the problems of risks inherent in gene technologies, which pose a potential danger of a destructive impact on the environment; analyzes the possibilities and prospects for controlling these risks using the mechanisms of international law. The lack of a unified approach in the legislation and practice of the application of international law in the countries most actively using gene technologies is stated. These provisions significantly complicate the search for consensus between the subjects of international law and increase the likelihood and danger of causing significant harm in the course of targeted manipulation of genomes. It is noted that the current regulation of research practice in international documents does not correspond to the current level of genetic engineering. Particular attention is paid to the safety of research laboratories and the analysis of incidents with different risks to human life and health. On this basis, the question is raised about the ability of legal systems to cope with the risks of dangerous consequences of such incidents. The need for a unified approach and the development of an international agreement in the field of genetic research is emphasized on the basis of the system of principles for regulating research in this area proposed by the authors.
\end{abstract}

\section{Introduction}

Advances in genetic engineering have become a challenge for legal science. There are many risks involved in genetic engineering. They are assessed ambiguously. This disorients society and its institutions in the development of effective legal regulation of the relevant area. On the one hand, there is a high likelihood of new threats to humans and the environment; on the other hand, genetic technologies open up new opportunities for medicine and biology.

The Nuffield Council on Bioethics (an independent body evaluating ethical issues in biology and medicine) noted that, first, genome editing challenges current regulatory systems. Second, differences in the rate of development of research and innovation versus the rate of change in regulatory systems (for example, legislation, institutional structures, regulatory policies and procedures, and the development of public moral consensus) can exacerbate conceptual inconsistencies, increase anxiety, and create mistrust among stakeholders [1].

Scientists, making fundamental discoveries in genetic engineering, faced ethical problems, while realizing that in the absence of clear social and legal norms, the risks of potential threats become difficult to manage. As sociologists have long noted, modern society is a society of risks. The law, which is conservative (and this is not always a negative factor), should be an adequate tool for timely response to rapidly occurring social processes, including the development of new biotechnologies.

\section{Results}

One of the objective consequences of genetic engineering is its destructive impact on the environment, which, ultimately, can become catastrophic. Currently, humanity faces a dilemma. Researchers can threaten the existence of ecosystems by introducing new genetically modified organisms into nature (deliberately or accidentally). On the other hand, this is a chance to restore the population of endangered or already extinct animal species, to solve the global warming.

Currently, scientists distinguish three approaches to restoring the population of extinct animal species crossing of living species that have the features of extinct animals; cloning and genetic engineering (CRISP-Cas 9 technology) [2]. Meanwhile, there are very important questions. To what extent can humanity interfere with the natural development of living nature and influence evolutionary processes? Wouldn't this kind of change lead to disastrous consequences? What is the role of law as a social instrument in protecting the interests of humanity from interference with the environment?

Criminal law and criminology have a critical role to play in ensuring the safety of society in the use of gene technologies and cloning, regulating some aspects of activities that can cause risky situations that threaten the

\footnotetext{
Corresponding author: ula-sl@mail.ru
} 
existence of a person and society. However, this task is complicated by the fact that at certain stages of the emergence of new biotechnologies, specialists find it difficult to assess possible risks and threats.

In our study, we have highlighted the risks of gene technologies that can have a devastating impact on the environment. We do not rank these risks according to the degree of their public danger and the likelihood of occurrence of dangerous consequences. Any of them carries a real the threat of dangerous consequences. We have identified the following risks:

1) the danger of deliberate manipulation of genomes in the absence of legal regulation of gene research;

2) in the absence of unified international legal instruments, the possibility necessary consensus among actors international law regarding gene technologies will continue decline;

3) widespread use of gene technologies in the private sector, where the possibilities of control are much lower than those in the state sector;

4) increased risks associated with laboratory safety.

Humanity has already faced the main risk associated with gene research - the deliberate manipulation of genomes in the absence of legal regulation.

While the legal community is trying to start talking about legislative rules for regulating gene technologies, completely different practices are developing in the world. A study of the legislation of countries that actively use gene technologies shows what rules are applied in the world.

In the United States, for example, editing the human genome is not prohibited, but there is currently a moratorium that can be lifted at any time. Attempts to resolve this issue arose even at the beginning of the use of gene technologies. In 1977-1978, the US National Institutes of Health introduced several bills to regulate recombinant DNA technology, but they were not even considered. In the early 1980 s, all genetic research had to be carried out in accordance with the "Guidelines" developed by the US National Institutes of Health; however, researchers acknowledge that these guidelines are often ignored by them.

Great Britain became the first country where the issue of the use of genetic technologies was legally regulated. In 1978, the country adopted "the Health and Safety (Genetic Manipulation) Regulations". It was the first legal document to regulate the practice of using genetic technology; however, it drew sharp criticism from the scientific community, as it was seen as an encroachment on the freedom of scientific research. UK legislation allows for the technology of modifying the human genome [3].

Currently, the European Union is the only region in the world that has established a regulatory framework for biomedical research, but this legislation is full of contradictions, gaps and unresolved issues [4]. The EU countries have adopted the Convention for the Protection of Human Rights and Dignity of the Human Being with regard to the Application of Biology and Medicine (Convention on Human Rights and Biomedicine) (Oviedo, 1997), as well as additional protocols to it. The practice of the European Court of Human Rights concerning the protection of human embryos is being formed. With regard to the application of biotechnology, the EU Directive on the legal protection of biotechnological inventions (98/44 / EC), the Directive on the intentional release into the environment of genetically modified organisms (2001/18 / EC) and a number of other directives apply.

Meanwhile, in China, India, Ireland and Japan, the ban on genome editing is not established at the legislative level, but at the level of guidelines [5].

In Russia, the Federal Law on State Regulation in the Field of Genetic Engineering Activities is in force, which determines the relations in the field of natural resource management, environmental protection, environmental safety and human health protection arising from the implementation of genetic engineering activities. It emphasizes that the procedure for the implementation of genetic engineering activities and the application of its methods to humans, tissues and cells in the human body, with the exception of gene diagnostics and gene therapy, are not subject to regulation by this law. Since 2002, the country has a temporary ban on human cloning. Other legislative acts in force on the territory of Russia regulate only certain aspects of the use of genomic data.

Gaps in the social and legal regulation of gene technologies, as well as the absence of any unified norms at the international level, lead to an increasing gap in the regulation of this activity at the national level; moreover, it is necessary to take into account the peculiarities of scientific and legal cultures in different countries.

The professional community is trying to develop uniform rules for the use of gene technologies. For example, the Declaration of Helsinki - Ethical Principles for Medical Research Involving Human Subjects. However, this approach cannot be considered effective. The risks of disregarding these rules remain quite high.

As for living organisms, the Cartagena Protocol on Biosafety to the Convention on Biological Diversity (2000) applies to them. It regulates the transboundary movement, transit, processing and use of all living modified organisms that may adversely affect the conservation and sustainable use of biological diversity, as well as certain risks to human health. An important part of the Cartagena Protocol on Biosafety is the basic principles of risk assessment and methodologies for determining them. This international instrument is based on the precautionary principle enshrined in the Rio Declaration on Environment and Development. Accordingly, in cases where there is a threat of serious or irreversible damage, the lack of full scientific confidence is not used as a reason to delay the adoption of cost-effective measures to prevent adverse changes in the state of the environment.

In 2010, pursuant to Article 27 of the Cartagena Protocol, the Nagoya - Kuala Lumpur Supplementary Protocol on Liability and Redress. This document is based on one of the basic principles of international environmental law - "the polluter pays". The Protocol entered into force in 2018, and 41 states are parties to it.

The need for legal regulation of the problems of gene technology in relation to biological formations that 
are capable of transferring or replicating genetic material is obvious. As one of the possible consequences of the rapidly developing synthetic biology, experts call the violation of the established specification of species (the creation of synthetic genes, transgenes, complex synthetic, organic components, or even organisms). It is extremely difficult to predict the consequences of these processes today.

Without denying the importance of the Cartagena Protocol, we note that at the present time some of its provisions do not quite correspond to the level of new discoveries in gene technologies. In particular, it is unclear whether new methods of editing the genome of plants and other living organisms fall within the scope of this document, whether organisms obtained as a result of genome editing are "living modified organisms". It should be borne in mind that many countries have not ratified this protocol, and the United States is not a member state.

Thus, over time and in the absence of unified international norms, the possibility of finding a consensus between the subjects of international law in the practice of using gene technologies decreases.

Since the 1980s, the main risk in the use of gene technologies was considered to be widespread in the private sector, where the effectiveness of control is lower than in the state. The potential profits of pharmaceuticals and other companies with multi-million dollar budgets make it difficult to objectively assess the dangerous consequences of genetic engineering experiments. On the other hand, it is thanks to the financial investments of private companies that the implementation of some large and socially useful projects has become possible. For example, a change in the genome of some crops has led to the appearance on the consumer market of soybeans with a reduced content of trans fats, canola with a low content of saturated fats and wheat with a reduced content of gluten. Genetically modified foods can help tackle the global problem of hunger. However, Article 22 of the Cartagena Protocol refers to facilitating the involvement of the private sector where necessary.

\section{Discussion}

In January 2021, scientists introduced the black-footed ferret (lat. Mustela nigripes) named Elizabeth Ann to the public, which is a genetic copy of the ferret named Will, who died in 1988, whose remains were frozen at the beginning of genetic research [6]. Similar experiments were performed in the United States before. In 2020, an extinct species, the Mongolian wild horse ("Przewalski's horse" - lat. Equus przewalskii), was cloned in Texas [7]. In the state of Wyoming, a "frozen zoo" has been formed, where a database of cells of more than 1100 species and subspecies of animals from all over the world is collected [8].

However, not all animal cloning experiments have been successful. In 2009, the first attempt at cloning an extinct Pyrenean goat ended in the death of a clone, which died seven minutes after its birth (due to a defect in the lungs) [9].
Currently, several groups of researchers are simultaneously engaged in projects to clone the "woolly mammoth" (lat. Mammuthus primigenius), which became extinct 4 thousand years ago, and the "passenger pigeon" (lat. Ectopistes migratorius), which was exterminated by the beginning of the twentieth century. The return of mammoths to the wild will help transform the Arctic tundra into pastures, according to Harvard University expert George Church [2]. Russian scientists also speak about the importance of such scientific research. Ecologist S. Zimov, founder of the Permafrost Research Center in Yakutia (Pleistocene Park), proposes to reverse the ecosystem transformation that took place 10 thousand years ago. In his opinion, the return of mammoths and other animals to their habitat will help return the lands of the tundra to the state in which they were thousands of years ago; pastures will have a cooling effect on the climate and save the planet from methane emissions [10]. The return of the "passenger pigeon" population should play a similar role in reforestation.

Repeatedly in the history of biomedicine scientists have declared a moratorium on research, knowing which "Pandora's box" they are opening. One of the founders of genetic engineering, Paul Berg, who first carried out gene splicing in 1972 and obtained recombinant DNA, suspended experiments on its introduction into the cells of living organisms for ethical reasons. $\mathrm{He}$ and 11 colleagues issued a statement ("Berg's letter") expressing concern about the potential dangers of some genetic engineering research [11]. In 2019, as genetic engineering reached a qualitatively new stage of development, a group of 18 scientists and bioethics called for a global moratorium on the editing inherited DNA in to create genetically modified babies [12]. Thus, scientists, having colossal opportunities in genetic technologies, solving another scientific problem that can radically change the social structure of society, are trying to start a dialogue with society and outline the optimal boundaries.

At the same time, there are cases when researchers neglect scientific ethics and the interests of society. The trial in China in 2019 gave rise to reflection on the need for universal legal mechanisms in the application of gene technologies. The Shenzhen City Court sentenced the Chinese researcher to three years in prison with an additional fine of 3 million yuan for the crime under Article 336 of the Criminal Code of the People's Republic of China "Illegal Medical Practice", and his colleagues. The defendants used genome-editing technology (CRISPR); this has led to genetic changes in newborns whose fathers are HIV-positive and mothers are HIV-negative [5]. Based on the explanations of the Supreme People's Court of the People's Republic of China about the concept of illegal medical practice, which does not correspond to the conduct of the accused, this judgment is questionable. Researchers who analyzed the above court case note that the defendant could be accused of committing a crime under Article 280 of the Criminal Code of the PRC "Falsification of documents", as he forged the permits of the Medical Ethics Committee of the hospital where genetically modified 
embryos were implanted. However, the Chinese authorities considered it appropriate to apply a different criminal law [14].

In China, as in most countries, such precedents are not regulated at the legislative level. The above example points to a legal impasse in which the justice of the People's Republic of China finds itself.

Attempts to develop unified international rules have been made on several occasions. In February 1975, at the initiative of Paul Berg, an international conference was organized in California, called the Asilomar Conference on Recombinant DNA; along with biologists and doctors, lawyers also took part in it. The conference resulted in the adoption of guidelines to ensure the of recombinant DNA technology.

Following the publication of the results of the experiment described above on human embryonic cells in China, the US National Academy of Medicine, the Royal Society of Great Britain and the Chinese Academy of Sciences convened the International Summit on Human Genome Editing, which highlighted the need for a permanent global forum. Since then, statements on ethical and social issues of genome editing have been adopted regarding various issues of its application [14]. They were initiated by the German National Academy of Sciences, the US National Academy of Sciences, the Nuffield Bioethics Council, and other organizations. The international community has endorsed the Declaration of Helsinki - Ethical Principles for Medical Research Involving Human Subjects (last revised in 2013).

These documents, due to their optional nature, can hardly be a deterrent. Meanwhile, the risk of significant harm in the targeted manipulation of genomes is constantly increasing.

Risks associated with ensuring the safety of research laboratories. In the $1970 \mathrm{~s}$, research and scientific manipulation of bacterial genes began in a number of London laboratories. In 1978, in Birmingham (UK), there was a fatal case of smallpox infection by J. Parker, a photographer at the University of Birmingham School of Medicine. There was a smallpox laboratory authorized by the World Health Organization. In 1979, the Birmingham Magistrates' Court closed the case against laboratory personnel suspected of violating the Workplace Safety Act due to insufficient evidence. In 1980, further investigation was carried out. The commission concluded that J. Parker contracted smallpox in a university laboratory in one of three ways: air through the ventilation system, through personal contact or through contact with contaminated equipment. Additional investigation could not establish a more precise cause. A working group was set up by the Department of Health and Human Services to develop recommendations on "laboratory use of dangerous pathogens", on the basis of which a code of practice in clinical diagnostic laboratories was developed.

Dangerous incidents related to laboratory experiments have occurred many times. In 1976, researchers published the results of a retrospective morbidity survey among 21,000 UK laboratory workers, which identified 21 cases of tuberculosis, 35 cases of hepatitis, 37 cases of bacterial dysentery [15].
Earlier in the United States, there was a series of incidents with scientists and technical personnel engaged in the development of bacteriological weapons. Between 2008 and 2012, more than 1,100 laboratory incidents involving bacteria, viruses, and toxins were reported to US federal regulators with significant risk to humans [16]. Unfortunately, the list of such incidents can be continued. Meanwhile, we are talking about the most developed countries, where high safety standards for the implementation of socially dangerous activities are ensured.

Scientists all over the world are experimenting with viral genomes. It is no coincidence that one of the main versions of the origin of the SARS-CoV-2 virus is associated with laboratory experiments. Disputes between scientists about the origin of the virus continue. In February 2020, The Lancet published an appeal by 27 scientists condemning conspiracy theories about the unnatural origin of COVID-19. However, long before the virus emerged, many scientists warned of the potential risks. Humanity has entered the "golden age" of genetic research on coronaviruses. In 2016, a report by Gryphon Scientific, a consulting firm commissioned by the US National Biosafety Advisory Board, noted that increasing the transmissibility of coronaviruses could significantly increase the likelihood of a global pandemic due to a laboratory accident.

If the laboratory origin of the SARS-CoV-2 virus is proven and it gets into the environment as a result of deliberate or careless actions of personnel, will legal institutions be able to cope with this situation? For a number of reasons, such an outcome seems unlikely.

\section{Conclusion}

In the field of genetic research, the number of risks and the likelihood of dangerous consequences for society are constantly growing. In these conditions, the need to develop and adopt a unified international agreement in this the area is obvious.

Safety in genetic research should be based on the following principles:

1) the principle of adequate assessment of the risks of genetic technologies for the environment and humanity;

2) the principle of compliance of legal institutions with the level of scientific and technological development of society;

3) ban on editing the human genome for nonmedical reasons;

4) the principle of openness of scientific research related to genome editing.

This, in our opinion, is the system of priorities that should be taken as the basis for an international document regulating the problems of the safety of genetic research.

\section{References}

1. Nuffield Council on Bioethics. Genome editing: An ethical review (2016). Retrieved from: 
http://nuffieldbioethics.org/project/genomeediting/ethical-review-published-september-2016

2. D. Shultz, Should we bring extinct species back from the dead? (2016) Retrieved from: https://www.sciencemag.org/news/2016/09/shouldwe-bring-extinct-species-back-dead

3. Y. Cripps, A legal perspective on the control of the technology of genetic engineering, The Modern Law Review, 4(44) (1981)

4. J. Almqvist, P.R. Romano, The Regulation of Human Germline Genome Modification in Europe. In: A. Boggio, C. Romano, J. Almqvist (Eds.), Human Germline Genome Modification and the Right to Science: A Comparative Study of National Laws and Policies (Cambridge University Press, 2020). pp. 155-216.

5. S. Liu, Legal reflections on the case of genomeedited babies, Global Health Research and Policy, 5, 24 (2020).

6. D. Main, A black-footed ferret has been cloned, a first for a U.S. endangered species (2021). Retrieved from:

https://www.nationalgeographic.com/animals/article /black-footed-ferret-clone-conservation-milestone

7. Cells at San Diego Zoo lead to cloning of endangered horse (2020). Retrieved from: https://apnews.com/article/technology-horses-asiasan-diego-mongoliadc90adc896b923a96ce12e1720111deb

8. Scientists clone the first U.S. endangered species (2021). Retrieved from: https://www.nbcnews.com/news/animal- news/scientists-clone-first-u-s-endangered-speciesn1258310

9. J. Bove, Pyrenean Ibex Facts (2021). Retrieved from: https://www.thoughtco.com/profile-of-thepyrenean-ibex-1182003

10. A. Burenkov, How Siberia can save the world from an ecological catastrophe (2019). Retrieved from: https://strelkamag.com/ru/article/kak-sibir-mozhetspasti-mir-ot-ekologicheskoi-katastrofy

11. Berg et al., Potential Biohazards of Recombinant D.N.A. Molecules, Science, 303 (1974)

12. E. Lander, F. Baylis, E. Zhang Charpentier, et al., Adopt a moratorium on heritable genome editing, Nature, 567, 165-168 (2019)

13. I. Kozachenko, D.N. Sergeev, Genetic research: legislation and criminal policy: monograph, pp. 171-183 (2021).

14. C. Walch-Solimena, Discussion paper focusing on the scientific relevance of genome editing and on the ethical, legal and societal issues potentially involved (Ethics Council of the Max Planck Society). Retrieved from: https://www.mpg.de/13811476/DPGenome-Editing-EN-Web.pdf

15. R. Williams, In pursuit of safety, J. Clin. Pathol., 34, 232-239 (1981). Retrieved from: https://jcp.bmj.com/content/jclinpath/34/3/232.full.p df

16. N. Baker, The Lab-Leak Hypothesis For decades, scientists have been hot-wiring viruses in hopes of preventing a pandemic, not causing one. But what if ...? Retrieved from: https://nymag.com/intelligencer/article/coronaviruslab-escape-theory.html 